\title{
Development of spatial-design thinking in architecture education
}

\author{
Ludmila Danchenko ${ }^{1 *}$ [0000-0001-6541-8406] \\ ${ }^{1}$ Kazan State University of Architecture and Engineering, 420043, Zelenaya st., Kazan, Russia
}

\begin{abstract}
The paper discusses the peculiarities of developing spatialdesign thinking of future architects and determining the levels of its formation. The peculiarity of this work is in revealing the sequence of actions and operations of spatial-design thinking during the architect's training as well as applying the modified design-analog method suggested by the authors. The proposed method has a practical orientation. It does not contradict the methods used, and has a wider range of applications in comparison with traditional methods. The article discusses the prospects for the development of the proposed method.
\end{abstract}

Keywords: spatial and design thinking, shaping, architectural design, geometry, graphics, level.

\section{Introduction}

Trends in the development of modern architecture and construction technology expand the design possibilities, the mobility of the architect and his/her creative potential. At the same time, there are increasing requirements for the future architect's competence as an ability to create an original, geometrically grounded architectural object and prepare its design solution. This raises the problem of formation of spatial-design thinking, its levels and structuring, and general geometric characteristics. [1,2] Graphic information technology packages, as a tool, reproduce, visualize the concept in the form of a drawing, but the idea of shaping, modeling structures belongs to the architect. Visualization can be the apparatus of application of spatial-design thinking [3].

Geometric characteristics of spatial-design thinking are manifested primarily through the variety, complexity of architectural forms, their geometry and harmonization $[3,4]$.

The aim of the study is to identify the features of spatial-design thinking of future architects and to determine the levels of its formation in the classes of graphic training of architectural students. In the system of general architectural training, its geometricalgraphic component, descriptive geometry is directly related to the study of the possibilities of visualization of architectural objects, their shaping, modeling and construction. The methodology of professional activity in architectural education manifests itself, first of all, in mastering the main method - «architect's method», which consists in aspiration to harmonization of architectural forms, space and its elements, to their originality and diversity [4-7].

\footnotetext{
*Corresponding author: $\underline{\text { d9700@yandex.ru }}$
} 
Many modern architectural schools and workshops in design issues are based on the manifestos of famous architects developing parametric design, nonlinear architecture, and the paradigm of free form [3]. In this context, form design is closely related to BIMtechnologies, the role of which is quite great in architectural education $[3,4,5,6]$. Understanding the problem of spatial-design thinking is also associated with ecological concepts, through the study of design based on bio-tech, eco-tech [6, 7]. History of architecture shows classical methods of form harmonization and ways of its representation in the drawing. The study of the historical context of architectural creativity, for example, the works of Leonardo Da Vinci are of great importance in the question of development of spatial-design thinking [7-11].Traditionally spatial-design thinking is defined as the creation of spatial images, their representation and operation with them in the process of practice and creativity. The methodology of spatial-design thinking development depends on the ideas of formation in architecture and represents a special kind of thinking activity connected with the orientation in the theoretical and practical space. One of the key qualities of an architect is the ability for visualization - the ability to scroll an object in the head, to break it into parts or to change it. This ability is directly related to the methodology of professional activity, understanding of the design process [12, 13].

Some studies, along with the development of spatial and design thinking, suggest the formation of associative perception and display of architectural ideas [4].

Analysis of works on the formation of spatial-design thinking allowed identifying the main operations of creating a design image, mental manipulation of two-dimensional or three-dimensional objects: creation of a visual image; changes in its position in space; changes in the spatial structure of the object; a set of changes in structure and position in space $[3,4]$.

In order to develop the ability to mentally create an image, a set of tasks in descriptive geometry related to shape formation in architecture was developed. The design component, in this context, is determinative and the learning process is based on the sequence of actions and operations in accordance with the technology of application of the modified designanalog method of teaching the future architect the basics of creating an original, harmonious form [14-16].

\section{Methods}

The geometry of an architectural concept manifests itself through the morphology of the geometric form (clarity of lines, their outline, location of points, definition of the plane, position in space, etc.) and gives a representation of the shape of the architectural object. Ways of graphic representation of the complete concept involve the development of practical skills of visualizing the mentally created image and elaboration of its individual details. The basis of such visualization is the concept of projection (orthogonal projections, axonometry and perspective). It is through mastering the methods of creating a graphic representation of a mentally created image of the future object, understanding its position in space, the geometry of composition, the technology of shaping occurs comprehension of the «architect's method». Spatial-design thinking is the interaction of mental creation of an architectural image, its spatial structure, with the skills of designing by modeling and positioning it in space, as well as with the ways of graphic visualization at all stages of design, including the process of sketching.

The peculiarity of the architect's design thinking is connected with the developed perception of reality, its aspects, the ability to see the result of design, using the procedures of displaying the object within the framework of professional activity $[4,5,6]$.

Geometric knowledge and technology of image reproduction are mastered by students during the study of geometry of form formation within the discipline «Descriptive 
geometry», which is basic and necessary for comprehension of «architect's method» in the classes of the core discipline «Architectural design».

It is traditionally believed that this discipline contributes to the formation of spatial thinking and understanding of space in general. In architectural education descriptive geometry plays an important role, as it considers the rules and laws of spatial forms on the plane, wherein a plane image is a geometric model of the spatial object, its perspective and axonometric projections, which has a direct relation to the formation of space design thinking in the future architect [16-19].

The structure of spatial-design thinking has the following components:

1. Reproductive components: representation of an abstract geometrical image, analysis of its location in space and its morphological characteristics; transformation of an image, its movement; change of its position in space; projective transformations.

2. Productive-creative components: changing the structure of the object by adding elements, their combinations; combining different images into an integral composition; simultaneous change of the form, structure, position of the image and representation of the integral form from different sides, rotating it [19].

The analysis of the geometric image, which consists of abstract geometric images, is the basis for understanding the design of the architectural object and, accordingly, allows us to read the projection image - drawing, that is, the structural-spatial representation. Thus, the method of descriptive geometry is the graphic representation and study of spatial forms with the help of the drawing. This forms the skills in depicting spatial architectural compositions on the plane, that is, on the projection drawing. The main method studied in descriptive geometry is the method of orthogonal projection. Flat images are obtained by the operation of projection. A set of images or drawing is subject to the requirements of reversibility, that is, the ability to uniquely identify all the geometric properties of the object, the relationship of elements and relationship with the environment, simplicity and clarity, the ability to make a spatial representation of the object as close to visual perception, as well as its compositional advantages on a flat image [19-21].

The surface in the drawing is defined by projections of the geometric part of its determinant. The projection operation provides the opportunity to solve a direct problem to depict a mentally created image. The mental image is formed in the student's mind, depicting the object in a specific environment. Geometric image - the reproduction of a mental image of an architectural object, its transformation through the operation of projection in the form of a drawing. In the field of architecture, a mental image of an object is usually defined as the basic idea or concept that requires mapping onto a plane. Thus, the analogous visual image of the model is transformed into an architectural concept through the morphology of its form (lines, planes, etc.) and through the constructive laws of shape formation. The morphological approach allows us to consider the geometry of the future object and the ways of its representation with the greatest clarity, i.e. to proceed from morphology of the image to an architectural and structural model.

The formation of spatial-design thinking of the future architect by means of graphics and descriptive geometry is subject to the level principles and continuity of training. The content component represents the transversal knowledge required primarily for the main discipline «Architectural Design». Graphic representation of architectural idea implies the development of visualization skills of mentally created image, elaboration of its individual details, which is associated with the concept of projection.

The levels of spatial-design thinking development are interconnected and interdependent in theoretical and practical terms. The peculiarity of the development of spatial-design thinking of future architects lies in the presence of propaedeutic level, the purpose of which is to prepare for the beginning of training in an architectural university. The task of propaedeutic training is to develop the skills of visual-image reproduction of 
the object, that is, the ability to display the object on the plane in orthogonal and axonometric projections. In addition, students master the tools, techniques of working with them, and the technology of making a drawing.

The main method of training - practical tasks with elements of the creative approach associated with the modeling of the subject, conducting analogies with the objects of conceptual architecture and design [19, 20-22]. Mastering of techniques, skills and basic knowledge is revealed in the process of competitive creative tests and allows considering the design training in the context of architectural practice.

The levels of spatial-design thinking development can be combined into blocks: reproductive, formative, productive.

Reproductive block.

Conceptual level. At this level, project thinking is formed through mastering the operational unit of displaying space and its elements. The morphological component of displaying space, its mental image, the conceptual apparatus of mutual arrangement of elements in the spatial structure, the possibilities of transformation and geometrical modeling through actions and operations are considered. In this case, the operations mean the graphic image technology, tools, constructions on the plane, including the use of computer technology. A set of operations allows performing the action of transition from a mental image to its graphic representation and further transformation.

Operational level. Concretization of elements of space, their mutual location, transformation and modeling is based on the change of position in space. This level is transitional and allows mastering manipulation of spatial structure on the basis of collinear correspondence, homology. Students master theoretical knowledge that is necessary for architectural shaping, construction.

Assessment of the formation of the reproductive level block is made on the basis of the current work on the consolidation of basic concepts and theoretical provisions using cognitive criterion.

Formative level. Directly related to the creation of the object. It determines actions on the transition from the mentally created image to a concrete object through mastering geometrical laws of surface creation and representation. The content component represents the classification characteristics of geometric shapes that determine the direction of shape formation. The definitions of this or that surface dictate ways of displaying the result in the form of a projection drawing. The abstract geometric image created by manipulation can be transformed into a concrete architectural form [22]. It is according to the content that this level can be considered as the most important in the process of spatial and projective thinking development. Students consider the classification characteristics of geometric forms, which determine the concept of shape formation, and display the result in the form of a projection drawing. An abstract geometric image defined by geometric conditions must be transformed into some architectural shape by manipulation. Evaluation criteria perception of the conditions of shape formation, reproduction of the form or visualization, understanding of the possibilities of modeling the resulting surface, modeling as a manifestation of interest in the chosen profession.

The productive block is connected directly with the architect's design activity through solving combined tasks, algorithms, experimentation.

The constructive-transformative level manifests itself through the synthesis of knowledge of the object of forming, the correction of actions for its creation and depiction. The mastering of this level relies on the application of the modified design-analog method to give a professional and practical context to the learning process. The student learns analog design, namely, geometric images are reproduced by him/her as peculiar models of integral object created in imagination, and then displayed on the plane. The practical significance of forming a constructive-transformative level of spatial-design thinking is 
enhanced by using a modified design-analog method of teaching, which is based on the relationship of architectural design with geometrical shaping, studied in the course of descriptive geometry, and is built in analogy with work in an architectural workshop [22, 23]. Assessment as much as possible is focused on practical activities: the ability to identify the applied geometric shapes and images in the depicted or imagined architectural object; productivity, manifested through an independent decision on the choice of form representation method, authenticity and angle of perception, as well as further modeling, research properties.

Design level. It is generalised and directly linked to the core discipline of Architectural Design and the operations of architectural imagery. Successful development of spatialproject thinking in this connection demonstrates the ability to compose an integral image in architectural, urban, constructive and geometrical contexts on the basis of combination of imagination and spatial imagination of the designed architectural object in several contexts. The features of spatial-design thinking at this level consist in the ability to see the anticipated result and procedures to achieve it, the perception of reality within the framework of design, creativity manifestation through the generation of ideas, concept creation, and the methodology of professional activity. Geometric-graphic training in this context has an applied nature, manifested in the ability to see the connections within the geometric object and its external environment, location in space, discretion visualization's technology. The assessment of the development of this level is based on the evaluation of creativity, namely the use of search procedures, originality of thinking and presentation, generation of ideas and approaches.

The spatial-design thinking levels during the experiment were characterised through students' understanding and recognition of simple geometric images, points, lines, planes, manipulating which allows creating and displaying surfaces according to geometric laws as analogues of an architectural concept. The ability to see and retain the mentally created integral architectural image, its structures and location in space is a feature of spatial-design thinking of a student - a future architect and design activity [22-24].

The results of the current assessment of 56 architectural students showed that $90 \%$ of them cope with the tasks of formation of curves, polyhedrons and surfaces of rotation, as well as the ways of their image. Successful completion of the tasks was related to the advisory role of the teacher as the project leader, which did not contradict the application of the modified design-analog method. $10 \%$ of the total number of students required additional explanation of the tasks related to architectural practice, which is dictated by gaps at the level of propaedeutic training.

\section{Results and discussion}

The results show that the development of the reproductive block of spatial-design thinking of the majority of students depends on mastering the theoretical framework and acquiring the skills to perform images. However some students have the ability to directly see the result on the basis of intuition, which is especially evident in the development of design skills in architectural education. Nevertheless, it is very important for students to acquire the performance qualities of an architect, i.e. the execution of technical documentation, the application of the regulatory framework.

The productive criterion defines the creative aspect of the development of spatial-design thinking related to the understanding of space. The student models the volume and space using their geometrical characteristics and creates conditions for the perception of the model. $18 \%$ of the students showed uncertainty about the solution when reproducing the mentally created image, which also required support and advice from the teacher as a workshop leader. 
The study of the problem showed that the understanding of space and its elements is an important component of architectural education in different architectural schools of the world. The development of spatial-design thinking through the study of geometry and graphics complements the methods of applying layout and graphic computer programs used in architectural schools in Europe and America. Modern methods of displaying space cannot be imagined without parametric modeling, but this aspect does not exclude the development of spatial-design thinking [3,25-27]. Architectural innovation requires combining a simple understanding of space and evolutionary design actions, which would allow moving in a given.

\section{Conclusion}

The identified features of the future architect's spatial-design thinking development allow emphasizing its reproductive and productive-creative levels. Reproductive levels are conceptual and operational.

Productive levels are constructive-transformative and design. The paper proposes to evaluate the design level based on the results of architectural design work.

We found that all levels are a united structure of interconnected elements, demonstrated that the application of the modified project-analog method provided a high level of spatialdesign thinking for architectural practice, showed that the creative component of architectural education depended on the mastery of both the conceptual apparatus of image construction and visualization practice, and discussed the prospects for spatial thinking of students-architects.

\section{References}

1. R.J. Milic, A. Nikezic, Communicating Heritage Through Intertwining Theory and Studio Based Course in Architectural Education, in Proceedings of $5^{\text {th }}$ INTBAU International Annual Event, Springer, (2018) DOI: 10.1007/978-3-319-57937-5_65

2. L.M. Enikeeva, V.Y. Chichkanova, E.I. Prokofev, Izvestija KGASU, 2(44) (2018).

3. Patrik Schumacher: Aquing for Elegans, Elegans, Architectural Design, 77(1) (2007)

4. S. Zubaidah, N.M. Fuad, S. Mahanal, E. Suarsini, JTSE, 14(4) (2017) DOI: 10.12973/tused.10214a)

5. A. Sangharchi, How to Imbue Practice with Tradition, in Proceedings of $5^{\text {th }}$ INTBAU International Annual Event, pp 22-30. Springer, (2018) DOI: 10.1007/978-3-31957937-5_3

6. De Botton A (2017) Architettura e felicità. Wikiquote, March 2017. https://it.wikiquote.org/wiki/Alain_de_Botton

7. L. Guardigli, A. Guidotti: True, False or Ordered? Some Architectures to Think About Reconstruction, in Proceedings of $5^{\text {th }}$ INTBAU International Annual Event, pp 45-55. Springer, (2018) DOI: 10.1007/978-3-319-57937-5_5

8. S. Brusaporci, Digital innovations in architectural heritage conservation: emerging research and opportunities (IGI Global, New York, 2017) DOI: 10.4018/978-1-52252434-2

9. L. Guerrini, Design as a Tool for Bringing New Life to the Historic Centre of L Aquila, in Proceedings of $5^{\text {th }}$ INTBAU International Annual Event, pp 115-124. Springer, (2018) DOI: 10.1007/978-3-319-57937-5_13

10.P.A. Funes, Use of Digital Collections as a Source of Architectural Treatises: Old Sources for the New Classical Architect, in Proceedings of $5^{\text {th }}$ INTBAU International Annual Event, pp 160-207. Springer, (2018) DOI: 10.1007/978-3-319-57937-5_17 
11. C. Bartoli (1550) L'architettura di Leon Batista Alberti. Lorenzo Torrentino, Firenze. Erara .http://www.e-rara.ch. Accessed 18 Feb 2017

12. Steven W. Semes, Gustavo Giovannoni: The Complete Architect, in Proceedings of $5^{\text {th }}$ INTBAU International Annual Event, pp 234-245. Springer, (2018) DOI: 10.1007/9783-319-57937-5_25

13. F.C. Invernizz, Learning Through Discovery: Different Techniques to Represent the Forgotten Cultural Heritage. Knowing Cervia's Colonia Varese across Historical Analysisand Contemporary Design, in Proceedings of $5^{\text {th }}$ INTBAU International Annual Event, pp 256-265. Springer, (2018) DOI: 10.1007/978-3-319-57937-5_27

14. F. Porfiri, G.L. Tacchi, The Relationship Between Real and Illusory Architecture: Survey and Analysis of the Ex-refectory of Orsoline's Convent in Rome, in Proceedings of $5^{\text {th }}$ INTBAU International Annual Event, pp 322-369. Springer, (2018) DOI: 10.1007/978-3-319-57937-5_34

15. L. Paris, Formal Innovation in Two Sixteenth-Century Helicoidal Staircases of Vignola and Mascarino, in Proceedings of $5^{\text {th }}$ INTBAU International Annual Event, pp 371-380. Springer, (2018) DOI: 10.1007/978-3-319-57937-5_39

16. A. Saunders, Baroque Topologies: Novel Approaches to Analysis and Representation of the Baroque Interior in the Era of Big Data, in Proceedings of $5^{\text {th }}$ INTBAU International Annual Event, pp 381-391. Springer, (2018) DOI: 10.1007/978-3-31957937-5_40

17. M.V. López, Carmen Sanz Contreras, J. Ramon Osanz Díaz, 3D Printing in Presentation Architecture Projects, in Proceedings of $5^{\text {th }}$ INTBAU International Annual Event, pp 636-643. Springer, (2018) DOI: 10.1007/978-3-319-57937-5_66

18. Joaquín A. Martínez-Moya, Jaume Gual-Ortí, M. Jesús Máñez-Pitarch, Physical Scale Models as Diffusion Tools of Disappeared Heritage, in Proceedings of $5^{\text {th }}$ INTBAU International Annual Event, pp 666-681. Springer, (2018)

19. F. Fischnaller, The Last Supper Interactive Project. The Illusion of Reality: Perspective and Perception, in Proceedings of $5^{\text {th }}$ INTBAU International Annual Event, pp 710-719. Springer, (2018) DOI: 10.1007/978-3-319-57937-5_73

20. Julián García, Juan Antonio Rodríguez, David Mencías, University Workshops as a Way of Dissemination of Architectural Traditions. The Case of the Tile Vault, in Proceedings of $5^{\text {th }}$ INTBAU International Annual Event, pp 1511-1527. Springer, (2018) DOI: 10.1007/978-3-319-57937-5_157

21. Martínez Moya, A. Joaquín, Gual Ortí, M. Jaume, Jesús Máñez Pitarch, Physical Scale Models as Diffusion Toolsof Disappeared Heritage, in Proceedings of $5^{\text {th }}$ INTBAU International Annual Event, pp 666-681. Springer, (2018) DOI: 10.1007/978-3-31957937-5_69

22. A.A. Tordesillas, N.G. Desvaux, M.A. Rogrignez, Towards a New Descriptive Geometry. A Teaching Innovation Project to the Architecture. Architectural Draughtsmanship: From Analog to Digital Narratives 1, 3-12 (2019). DOI: 10.1007/978-3-319-58856-8_1

23. L. Madrazo, Systems of Representation. A Space for Constructing Knowledge. Architectural Draughtsmanship: From Analog to Digital Narratives 1, 14-26 (2019) DOI: $10.1007 / 978-3-319-58856-8 \_2$

24. L. Augustin Hermandez, A. Fernandez-Moralez, M. Sancho-Mir, Teaching Strategies for the BIM Work Process. Architectural Draughtsmanship: From Analog to Digital Narratives 1, pp 62-74 (2019) DOI: 10.1007/978-3-319-58856-8_6

25. R. Valenti, S. Giuliano, E. Paterno, The Laboratory of Representation: on in the XXI Century, from the Study of Geometry to 3D Printing. Perspectives and Innovatively 
Coordinated Methodological Devices for an Experimental Teaching. Architectural Draughtsmanship: From Analog to Digital Narratives 1, pp 75-89 (2019) DOI: 10.1007/978-3-319-58856-8_7

26. M.V. Knyazeva, Izvestija KGASU, 1(47) (2019).

27. Tatyana Belavina, Tatyana Gorskaya, Meri Goulkanyan, Engineering and computer graphics for effective training in a construction university, IOP Conference Series: Materials Science and Engineering, 890 (012173) 2020 DOI: 10.1088/1757899X/890/1/012173 